\title{
Evidence for the Participation of the Neuron-Specific CDK5 Activator P35 during Laminin-Enhanced Axonal Growth
}

\author{
Gabriela Paglini, ${ }^{1}$ Gustavo Pigino, ${ }^{1}$ Patricia Kunda, ${ }^{1}$ Gerardo Morfini, ${ }^{1}$ Ricardo Maccioni, ${ }^{2}$ Santiago Quiroga, ${ }^{3}$ \\ Adriana Ferreira, ${ }^{4}$ and Alfredo Cáceres ${ }^{1}$ \\ 1/nstituto Mercedes y Martín Ferreyra, Consejo Nacional de Investigaciones Científicas y Técnicas (CONICET), 5000 \\ Cordoba, Argentina, ${ }^{2}$ Laboratorio Biología Celular y Molecular, Universidad de Chile, 5000 Santiago, Chile, \\ ${ }^{3}$ Departamento Quimica Biologica, CONICET, Universidad Nacional de Cordoba, 5000 Cordoba, Argentina, and 4Institute \\ of Neuroscience and Department of Cell and Molecular Biology, Northwestern University, Chicago, Illinois 60611
}

Cultures of cerebellar macroneurons were used to study the pattern of expression, subcellular localization, and function of the neuronal cdk5 activator p35 during laminin-enhanced axonal growth. The results obtained indicate that laminin, an extracellular matrix molecule capable of selectively stimulating axonal extension and promoting MAP1B phosphorylation at a proline-directed protein kinase epitope, selectively stimulates p35 expression, increases its association with the subcortical cytoskeleton, and accelerates its redistribution to the axonal growth cones. Besides, suppression of p35, but not of a highly related isoform designated as p39, by antisense oligonucleotide treatment selectively reduces cdk5 activity, lamininenhanced axonal elongation, and MAP1b phosphorylation. Taken collectively, the present results suggest that cdk5/p35 may serve as an important regulatory linker between environmental signals (e.g., laminin) and constituents of the intracellular machinery (e.g., MAP1B) involved in axonal elongation.

Key words: cdk5; p35; neurons; development; axon; growth cones; MAP1b; phosphorylation; antisense oligonucleotides; neuronal cultures
Developing neurons project axons toward their targets often over relatively enormous distances. At the distal end of these projections is the growth cone, a structure containing dynamic protrusions that sample a complex extracellular environment composed of adhesive substrates. Among these are a variety of extracellular matrix components, such as laminin, collagen, fibronectin, vitronectin, tenascin, and thrombospondin capable of promoting process outgrowth, elongation, and/or branching (Reichardt and Tomaselli, 1991).

Intracellular mechanisms provide structural elements, most notably microtubules, to maintain elongating neuronal projections and the transport of membranous organelles or cytoskeletal elements to the active growing tip of neuritic processes (Mitchison and Kirschner, 1988; Tanaka and Sabry, 1995). As the neuronal specific organization of microtubules depends on their high degree of spatial and temporal differentiation, a great deal of attention has been devoted to identify factors controlling microtubule organization in nerve cells. Current evidence favors the view that the regulation of microtubule assembly and stability during process formation is dependent on the expression of a particular set of proteins, known as microtubule-associated proteins or MAPs (Matus, 1988; Hirokawa, 1994; Maccioni and Cambiazo, 1995). Interestingly, all of the MAPs that have been directly implicated in axonal formation, such as MAP1b and tau

\footnotetext{
Received June 8, 1998; revised Sept. 9, 1998; accepted Sept. 11, 1998.

This work was supported by grants from Consejo Nacional de Investigaciones Científicas y Técnicas (CONICET), CONICOR, Fundación Perez-Companc, Fundación Antorchas (ABC Research Grant), and the Howard Hughes Medical Institute under an International Research Scholar Program to A.C. It was also supported by start-up funds from the Northwestern Institute of Neuroscience to A.F. P.K. is supported by a doctoral fellowship from CONICET. We thank Dr. L. Binder, N. Carri, and J. Avila for providing antibodies and J. Wong for cDNA probes.

Correspondence should be addressed to Alfredo Cáceres, Instituto Mercedes y Martín Ferreyra, Casilla de Correo 389, 5000 Córdoba, Argentina.

Copyright (C) 1998 Society for Neuroscience $0270-6474 / 98 / 189858-12 \$ 05.00 / 0$
}

(Cáceres and Kosik, 1990; Brugg et al., 1993; Esmaeli-Azad et al., 1994; Harada et al., 1994; DiTella et al., 1996; Edelman et al., 1996; Takei et al., 1997) are present at the distal end of growing axons, including the central and peripheral regions of growth cones (Ulloa et al., 1994; Brandt et al., 1995; Rocha and Avila, 1995; DiTella et al., 1996). Besides, there is an emerging body of evidence suggesting that the in vivo usage of MAPs is stimulated by environmental factors (Drubin et al., 1985; Ferreira and Cáceres, 1991; DiTella et al., 1996). Despite that, it is not yet clear how environmental clues, and particularly extracellular matrix molecules, may modulate the functional activity of MAP1b or tau. One obvious possibility is the local and temporal regulation of MAPs activity by phosphorylation (Avila et al., 1994; Tanaka and Sabry, 1995).

To begin testing this hypothesis, in previous studies we have shown that laminin, a molecule capable of selectively enhancing axonal outgrowth and promoting MAP1b phosphorylation, accelerates the redistribution of the cyclin-dependent kinase $5(\mathrm{cdk} 5)$ to the axonal growth cone and dramatically stimulates its activity (DiTella et al., 1996, Pigino et al., 1997). In addition, our results showed that cdk5 suppression by antisense oligonucleotide treatment reduced axonal elongation and decreased the phosphorylation status of MAP1b, as well as its binding to microtubules (Pigino et al., 1997). In the present study we present evidence about the mechanisms by which laminin may regulate cdk5 activity and MAP1b phosphorylation. The results obtained suggest that by regulating the expression and subcellular distribution of $\mathrm{p} 35$, a brain-specific activator of cdk5 (Lew et al., 1994; Tsai et al., 1994; Nikolic et al., 1995; Lee et al., 1996a; Chae et al., 1997) laminin stimulates cdk5 activity, MAP1b phosphorylation, and axonal elongation.

\section{MATERIALS AND METHODS}

Cell cultures. Dissociated cultures of cerebellar macroneurons were prepared as described previously (Ferreira et al., 1989; Cáceres et al., 1992; 
DiTella et al., 1996). Cells were plated onto polylysine-coated glass coverslips (12 or $25 \mathrm{~mm}$ in diameter) at densities ranging from 5000 to 15,000 cells per $\mathrm{cm}^{2}$ and maintained with DMEM plus $10 \%$ horse serum for $1 \mathrm{hr}$. The coverslips with the attached cells were then transferred to $60 \mathrm{~mm}$ Petri dishes containing serum-free medium plus the N2 mixture of Bottenstein and Sato (1979). All cultures were maintained in a humidified $37^{\circ} \mathrm{C}$ incubator with $5 \% \mathrm{CO}_{2}$.

To bind laminin to the substrate, polylysine-coated coverslips were soaked in DMEM containing mouse EHS laminin (Life Technologies, Gaithersburg, MD; Sigma, St. Louis, MO; or Boehringer Mannheim, Indianapolis, IN) at a concentration of $10 \mu \mathrm{g} / \mathrm{ml}$ (unless otherwise specified) overnight at $4^{\circ} \mathrm{C}$. In some experiments, laminin was directly added to the culture medium from a $1 \mathrm{mg} / \mathrm{ml}$ stock solution to make a final concentration of 10 or $20 \mu \mathrm{g} / \mathrm{ml}$ (DiTella et al., 1996). To block laminin activity, an affinity-purified rabbit polyclonal antibody against $\beta 1$-integrin (Carri et al., 1992) was directly added to the tissue culture medium at concentrations ranging from 100 to $200 \mu \mathrm{g} / \mathrm{ml}$.

Antisense oligonucleotides. Three antisense phosphorothioate oligonucleotides (S-modified) were used in the present study. One of them, designated RP1, consists of the sequence 5' CCCTTCGGCCGGACCACG 3', and it is the inverse complement of the nucleotides +1870 / +1887 of the rat cDNA for p35; the other one designated RP2 consists of the sequence 5' GACGACGCGACGGACCCG 3', and it is the inverse complement of the nucleotides $+914 /+931$ of the rat cDNA for p35 (Lew et al., 1994; Tsai et al., 1994). A third antisense oligonucleotide consists of the sequence AGCCGGCGGTCCCTGTCG, and it is the inverse complement of the nucleotides $+1094 /+1111$ of the rat cDNA for p39, an isoform of p35 (Tang et al., 1995). Analysis of a gene data base (GenBank) showed that the sequences selected have no significant homology with any other known sequence. The oligonucleotides were purchased from Quality Controlled Biochemicals (Hopkinton, MA); they were purified by reverse chromatography, and they were taken up in serum-free medium as described previously (Cáceres and Kosik, 1990; Cáceres et al., 1991, 1992; DiTella et al., 1996). For all the experiments the antisense oligonucleotides were preincubated with $2 \mu \mathrm{l}$ of Lipofectin reagent $(1 \mathrm{mg} / \mathrm{ml}$; Life Technologies) diluted in $100 \mu \mathrm{l}$ of serum-free medium. The resulting oligonucleotide suspension was then added to the primary cultured neurons at concentrations ranging from 0.5 to $5 \mu \mathrm{M}$. Control cultures were treated with the same concentration of the corresponding sense-strand oligonucleotides. For some experiments cultures were treated with a combination of tau and MAP1b antisense oligonucleotides as described previously (DiTella et al., 1996; Pigino et al., 1997).

Primary antibodies. The following primary antibodies were used in this study: a monoclonal antibody (mAb) against tyrosinated $\alpha$-tubulin (clone TUB-1A2, mouse IgG; Sigma) diluted 1:2000; a mAb against microtubule-associated protein MAP2 (clone AP14; Cáceres et al., 1992) diluted 1:500; a mAb against an integral Golgi membrane protein designated as TGN38 (clone 2F7.1; Oncogene Research Products, Calbiochem, MA; see also, Horn and Banting, 1994) diluted 1:200; an affinitypurified rabbit polyclonal antibody raised against a peptide corresponding to amino acids 2-21 mapping at the amino terminus of p35 (antibody N-20; Santa Cruz Biotechnology, Santa Cruz, CA) diluted 1:50 or 1:100; an affinity-purified rabbit polyclonal antibody raised against a peptide corresponding to amino acid residues 289-307 mapping at the $\mathrm{C}$ terminus of p35 (antibody C-19, Santa Cruz Biotechnology) diluted 1:50 or 1:100; an affinity-purified polyclonal antibody raised against a peptide corresponding to amino acid residues 349-367 mapping at the C terminus of the $39 \mathrm{kDa}$ isoform of p35 (Research Genetics, Huntsville, AL; see also Tang et al., 1995) diluted 1:50; an affinity-purified rabbit polyclonal antibody raised against a peptide corresponding to amino acid residues 284-291 mapping at the $\mathrm{C}$ terminus of cdk5 diluted 1:10, 1:50, or 1:100 (Santa Cruz Biotechnology; see also, Lee et al., 1996a); and a mAb raised against a peptide corresponding to amino acid residues 181-198 mapping at the $\mathrm{C}$ terminus of the mitotic inhibitor p27 (clone F-8; Santa Cruz Biotechnology) diluted 1:200. We also used several antibodies against MAP1b: mAb AA6, which recognizes a conserved nonphosphorylated and nonphosphorylatable epitope on MAP1b (mouse IgG; Sigma; Brugg et al., 1993; DiTella et al., 1996) diluted 1:50; mAb 150, which recognizes a proline-directed protein kinase- (PDPK) phosphorylated epitope (mouse IgM; Ulloa et al., 1993a,b, 1994; DiTella et al., 1996; Pigino et al., 1997) diluted 1:200; and rabbit antiserum 531 that recognizes the PDPK phosphorylatable epitope when it is dephosphorylated (Ulloa et al., 1993a,b, 1994; DiTella et al., 1996; Pigino et al., 1997) diluted 1:200.

Immunofluorescence. Cells were fixed before or after detergent extraction under microtubule-stabilizing conditions and processed for immu-
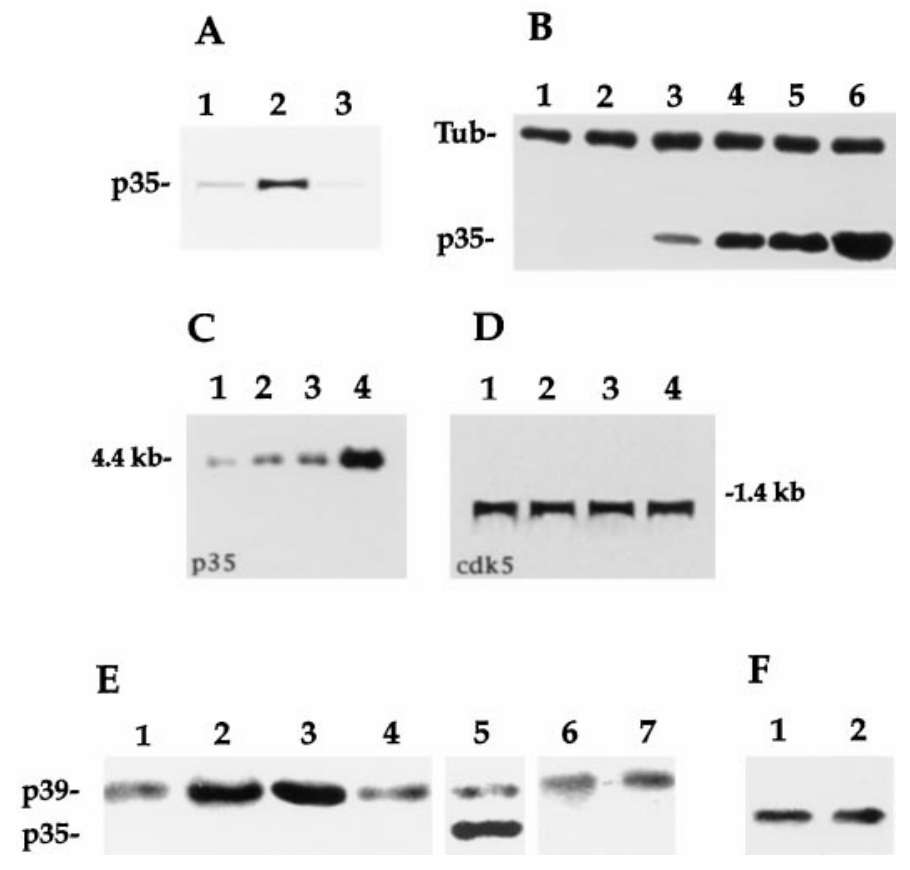

Figure 1. A, Specificity of the affinity-purified rabbit polyclonal antibody C19 diluted 1:200 $(0.5 \mu \mathrm{g} / \mathrm{ml})$ as revealed by Western blot analysis of cell extracts obtained from cerebellar macroneurons cultured on polylysine for 12 (lane 1) or 48 (lane 2) hr. The antibody labels a single immunoreactive protein species with an apparent molecular weight of $35 \mathrm{kDa}$. The staining generated by this antibody is completely abolished by neutralization with the corresponding purified peptide (lane 3). Ten micrograms of total cellular protein were loaded in each lane. $B$, Western blot analysis of whole-cell extracts reacted with the $\mathrm{C} 19$ antibody $(0.5 \mu \mathrm{g} / \mathrm{ml})$ revealed that laminin significantly increases p35 protein levels in cultured cerebellar macroneurons. Lanes 1-3, Extracts obtained 4, 12, and $24 \mathrm{hr}$ after plating from cells growing on polylysine; lanes $4-6$, idem but from cells growing on laminin. The blot was also labeled with a mAb against tyrosinated $\alpha$-tubulin diluted 1:500. Ten micrograms of total cellular protein were loaded in each lane. $C$, Northern blot analysis of p35 mRNA expression in cerebellar macroneurons cultured on polylysine for 12 (lane 1) or 24 (lane 2) hr, or on a laminin-containing substrate for 4 (lane 3) or 24 (lane 4) hr. $D$, An equivalent Northern blot to that shown in $C$ but probed with a radiolabeled cDNA probe for cdk5. Four micrograms of total RNA were loaded in each lane. E, Lanes 1-4, Western blot analysis of whole tissue extracts obtained from the cerebellar cortex of postnatal days 1 (lane 1), 7 (lane 2), 14 (lane 3), and adult (lane 4) rats, probed with the affinity-purified peptide antibody against p39 diluted 1:100 $(1 \mu \mathrm{g} / \mathrm{ml})$; each lane was loaded with $10 \mu \mathrm{g}$ of total protein. Lane 5 , Western blot showing the relative levels of p39 and p35 in a cerebellar extract obtained from an E18 rat embryo; the blot was reacted with the anti-p39 antibody diluted 1:50 $(2 \mu \mathrm{g} / \mathrm{ml})$ and with the N20 antibody diluted 1:200 $(0.5$ $\mu \mathrm{g} / \mathrm{ml}$ ); the lane was loaded with $10 \mu \mathrm{g}$ of total cellular protein. Lanes 6 , 7 , Western blot showing the relative levels of p39 in cell extracts from cerebellar macroneurons cultured on polylysine (lane 6) or laminin (lane 7) for $48 \mathrm{hr}$; the p39 antibody was used at a concentration of $2 \mu \mathrm{g} / \mathrm{ml}$, and $20 \mu \mathrm{g}$ of total cellular protein were loaded in each lane. $F$, Western blot showing the relative levels of the mitotic inhibitor p27 in cell extracts from cerebellar macroneurons cultured on polylysine (lane 1) or laminin (lane 2) for $24 \mathrm{hr} ; 10 \mu \mathrm{g}$ of total cellular protein were loaded in each lane.

nofluorescence as previously described (DiTella et al., 1996; Pigino et al., 1997; see also Black et al., 1994). For some experiments a mild extraction protocol that preserves cytoskeletal-membrane interactions was used (Nakata and Hirokawa, 1987; Brandt et al., 1995; Pigino et al., 1997). Cells were washed in extraction buffer ( $80 \mathrm{~mm}$ PIPES, pH 6.8, $1 \mathrm{~mm}$ $\mathrm{MgCl} 2,1 \mathrm{~mm}$ EGTA, 30\% v/v glycerol, and $1 \mathrm{~mm}$ GTP), incubated for $30 \mathrm{sec}$ with extraction buffer containing $0.02 \%$ saponin and washed with extraction buffer. Cell were then fixed for $1 \mathrm{hr}$ at room temperature with $2 \%(\mathrm{w} / \mathrm{v})$ paraformaldehyde, $0.1 \%(\mathrm{v} / \mathrm{v})$ glutaraldehyde in extraction buffer, washed with PBS, permeabilized with $0.1 \%$ (v/v) Triton X-100 in 
PBS for $30 \mathrm{~min}$, and finally washed in PBS. The antibody staining protocol entailed labeling with the first primary antibody, washing with PBS, staining with labeled secondary antibody (fluorescein- or rhodamine-conjugated) and washing similarly; the same procedure was repeated for the second primary antibody. Incubations with primary antibodies were for 1 or $3 \mathrm{hr}$ at room temperature, whereas incubations with secondary antibodies were performed during $1 \mathrm{hr}$ at $37^{\circ} \mathrm{C}$. The cells were analyzed with a Zeiss LSM 410 confocal scanning microscope or with an inverted microscope (Carl Zeiss Axiovert $35 \mathrm{M}$ ) equipped with epifluorescence and differential interference contrast (DIC) optics and photographed using $40 \times, 63 \times$, or $100 \times$ objectives (Carl Zeiss) with Tri X-Pan or T-MAX 400 ASA film (Eastman Kodak, Rochester, NY). Exposure times ranged from 45 to $60 \mathrm{sec}$.

For some experiments the relative intensities of tubulin, cdk5, p35, or MAP1b immunofluorescence were evaluated in fixed unextracted cells or in detergent-extracted cytoskeletons using quantitative fluorescence techniques as described previously (DiTella et al., 1994, 1996; Pigino et al., 1997). To image labeled cells, the incoming epifluorescence illumination was attenuated with glass neutral density filters. Images were formed on the faceplate of a Silicon Intensified Target (SIT) camera (Hamamatsu, Middlesex, NJ), set for manual sensitivity, gain, and black level. They were digitized directly into a Metamorph/Metafluor Image Processor (Universal Imaging Corporation, West Chester, PA) controlled by a host IBM-AT computer. Fluorescence intensity measurements were performed pixel by pixel along the longitudinal axis of identified neurons. Using this data, we then calculated the average fluorescence intensity within the cell body, inner, middle, and distal third of identified neurites (either minor processes or axons). In addition, in some cases the distribution of cdk5 and that of microtubules labeled with antibodies against tyrosinated $\alpha$-tubulin were analyzed using high resolution fluorescence microscopy and ratio image analysis with the image processing menu of the Metamorph/Metafluor system.

Isolation of growth cone particles by subcellular fractionation. Fetal rat brain (18 d of gestation) was fractionated according to Pfenninger et al. (1983) (see also Quiroga et al., 1995) to obtain growth cone particles (GCPs). Briefly, the low speed supernatant (L) of fetal brain homogenate (H) was loaded on a discontinuous sucrose gradient in which the $0.75 \mathrm{M}$ and $1 \mathrm{~m}$ sucrose layers were replaced with a single $0.83 \mathrm{~m}$ sucrose step. This facilitated collection of the interface and increased GCP yield without decreasing purity (Lohse et al., 1996). The $0.32 \mathrm{M} / 0.83 \mathrm{M}$ interface or A fraction, was collected, diluted with $0.32 \mathrm{M}$ sucrose, and pelleted to give the GCP fraction. This was resuspended in $0.32 \mathrm{M}$ sucrose for experimentation. It is worth noting that this preparation (GCPs) has been extensively characterized by electron microscopic (Pfenniger et al., 1983; Li et al., 1992) and biochemical methods. These studies have revealed that GCPs contain significant amounts of c-src (Helmke and Pfenniger, 1996), tau, GAP-43 (Lohse et al., 1996), and $\beta \mathrm{gc}$ (Quiroga et al., 1995), but lack detectable amounts of high molecular weight MAP2, glial fibrillar acidic protein, and vimentin (Lohse et al., 1996).

Western blot analysis. Changes in the levels of p35, p39, p27, cdk5, and microtubular proteins during the in vitro development of cerebellar macroneurons were also analyzed by Western blotting as previously described (DiTella et al., 1996; Pigino et al., 1997). Briefly, equal amounts of crude brain homogenates or whole-cell extracts from cultured cells were fractionated on $10 \%$ SDS-PAGE and transferred to polivinylidene difluoride membranes in a Tris-glycine buffer, $20 \%$ methanol. The filters were dried, washed several times with TBS (10 mM Tris, $\mathrm{pH} 7.5$, and $150 \mathrm{~mm} \mathrm{NaCl}$ ), and blocked for $1 \mathrm{hr}$ in TBS containing 5\% BSA. The filters were incubated for $1 \mathrm{hr}$ at $37^{\circ} \mathrm{C}$ with the primary antibodies in TBS containing 5\% BSA. The filters were then washed three times (10 min each) in TBS containing $0.05 \%$ Tween 20 and incubated with a secondary alkaline phosphatase-conjugated antibody (ProtoBlot western blot alkaline phosphatase system; Promega, Madison, WI) for $1 \mathrm{hr}$ at $37^{\circ} \mathrm{C}$. After five washes with TBS and $0.05 \%$ Tween 20 , the blots were developed with bromochloroiodolylphosphate $(15 \mu \mathrm{l}$ of a $50 \mathrm{mg} / \mathrm{ml}$ stock solution) and nitroblue-tetrazolium $(2.5 \mu \mathrm{l}$ of a $75 \mathrm{mg} / \mathrm{ml}$ stock solution $)$ in $10 \mathrm{ml}$ of alkaline phosphatase-detection buffer $(100 \mathrm{~mm}$ Tris, $100 \mathrm{~mm}$ $\mathrm{NaCl}$, and $5 \mathrm{~mm} \mathrm{MgCl2}$, pH 9.5). In addition, p35, p27, and $\alpha$-tubulin
Table 1. Changes in 335 protein levels in cerebellar macroneurons cultured in the presence or absence of laminin

\begin{tabular}{lllll} 
& \multicolumn{3}{l}{ Hours in vitro } & \\
\cline { 2 - 5 } Groups & 1 & 24 & 72 & 120 \\
\hline Polylysine & $230 \pm 25$ & $550 \pm 85$ & $1100 \pm 120$ & $2400 \pm 145$ \\
Laminin $(10 \mu \mathrm{g} / \mathrm{ml})$ & $245 \pm 45$ & $1850 \pm 110^{*}$ & $3050 \pm 85^{*}$ & $4100 \pm 110^{*}$ \\
$\begin{array}{l}\text { Laminin }(10 \mu \mathrm{g} / \mathrm{ml}) \\
\quad \text { plus anti- } \beta 1 \mathrm{integrin} \\
(150 \mu \mathrm{g} / \mathrm{ml})\end{array}$ & $260 \pm 75$ & $950 \pm 125^{*}$ & & \\
\hline
\end{tabular}

p35 protein levels were determined by quantitative Western blotting using ${ }^{125} \mathrm{I}$ protein A, as described in Materials and Methods. Each value represents the mean \pm SEM from measurements of five samples obtained from cerebellar cultures grown on $25 \mathrm{~mm}$ glass coverslips. Values are expressed in micrograms per milligram of total cellular protein. The anti- $\beta 1$ integrin was added to the tissue culture medium $1 \mathrm{hr}$ after plating (see also Pigino et al., 1997).

*Values significantly different from those found in the corresponding control group.

protein levels were measured by quantitative immunoblotting as described by Drubin et al. (1985) (see also DiTella et al., 1996). For such a purpose, immunoblots were probed with the corresponding primary antibody, followed by incubation with ${ }^{125}$ I protein A. Autoradiography was performed on Kodak X-omat AR film using intensifying screens. Autoradiographs were aligned with immunoblots, and p35 protein levels were quantitated by scintillation counting of nitrocellulose blot slices.

Immunoprecipitation. For immunoprecipitation cells were lysed in RIPA buffer containing $50 \mathrm{~mm}$ Tris-HCl, $\mathrm{pH} 7.5,150 \mathrm{~mm} \mathrm{NaCl}, 5 \mathrm{~mm}$ EDTA, pH 8.0, $1 \%$ Nonidet P-40, $0.5 \%$ sodium deoxycholate, $0.1 \%$ SDS, $5 \mathrm{~mm}$ DTT, $1 \mathrm{~mm}$ PMSF, $1 \mu \mathrm{g} / \mathrm{ml}$ aprotinin, and $1 \mu \mathrm{M}$ leupeptin. Two hundred micrograms of total cellular protein were then used for immunoprecipitation with the anti-p35 or anti-cdk5 rabbit antibodies. In all cases immunoprecipitation was performed as described by Tsai et al. (1993) (see also Pigino et al., 1997) using Protein G Plus agarose (Santa Cruz Biotechnology).

Northern blot analysis of $c d k 5$ and p35 expression. Total RNA from cultured cerebellar macroneurons was isolated sing the QuickPrep mRNA purification kit from Pharmacia (Pharmacia, Piscataway, NJ). Two micrograms of Poly(A)'RNA were resolved by gel electrophoresis (1.2\% agarose) and blotted to Hybond $\mathrm{N}^{\prime}$ membranes (Amersham International) by capillary action. Blots were baked for $2 \mathrm{hr}$ at $80^{\circ} \mathrm{C}$ and hybridized with a radiolabeled cDNA corresponding to either cdk 5 or p35 (a generous gift of Dr. Jerry Wang, Hong Kong University; see Lew et al., 1994) in 5\% SSPE (750 mM NaCl, $50 \mathrm{~mm} \mathrm{NaH}_{2} \mathrm{PO}_{4}$, and $5 \mathrm{~mm}$ EDTA, $\mathrm{pH}$ 7.4) after prehybridization under the same conditions. Blots were washed at $68^{\circ} \mathrm{C}$ in $2 \times \mathrm{SSPE}$ for $10 \mathrm{~min}$, twice in $1 \times \mathrm{SSPE}$ for 10 $\mathrm{min}$, and then autoradiographed at $-70^{\circ} \mathrm{C}$. Exposures times were for 24 or $72 \mathrm{hr}$.

Morphometric analysis of neuronal shape parameters. Images were digitized on a video monitor using Metamorph/Metafluor software. To measure neurite length, fixed unstained or antibody-labeled cells were randomly selected and traced from a video screen using the morphometric menu of the Metamorph as described previously (Cáceres et al., 1992; DiTella et al., 1994, 1996). The following neuritic shape parameters were evaluated: total length of minor processes per cell, total axonal length per cell, and total dendritic length per cell. All measurements were performed using DIC optics at a final magnification of $768 \times$. Differences among groups were analyzed by the use of ANOVA and Student Newman-Keuls test.

\section{RESULTS}

\section{Laminin stimulates p35 expression in cultured cerebellar macroneurons}

The monospecificity of the affinity-purified rabbit polyclonal antibody $\mathrm{C} 19$ raised against a peptide corresponding to amino acid

Fluorescence intensity measurements were performed in the cell body of cells maintained in culture for $24 \mathrm{hr}$; a total of at least 50 cells was analyzed for each protein and experimental condition. $D$, cdk5 histone H1 activity in control (lane 1) and RP1-treated (lane 2, $5 \mu \mathrm{M})$ cerebellar macroneurons. cdk5 was immunoprecipitated from cell homogenates after $1 \mathrm{~d}$ in vitro $(200 \mu \mathrm{g}$ of total cellular protein per sample) and kinase reactions performed as described in Materials and Methods. Films were exposed for $1 \mathrm{~d}$. E, Graph showing quantitation of cdk5 histone H1 activity in control, sense, and RP1or RP2-treated cultures, as revealed by Cerenkow counting of samples prepared as described in $D$. 


\section{A}

$\begin{array}{lllll}1 & 2 & 3 & 4 & 5\end{array}$

p35-

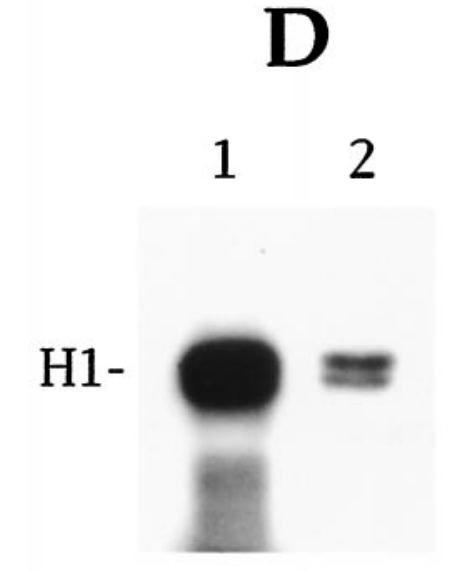

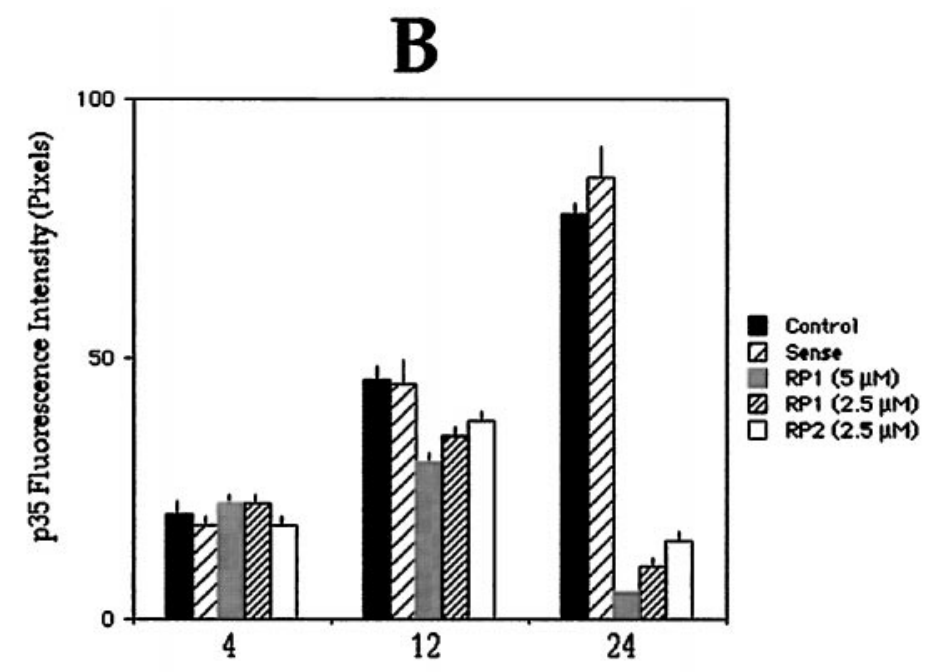
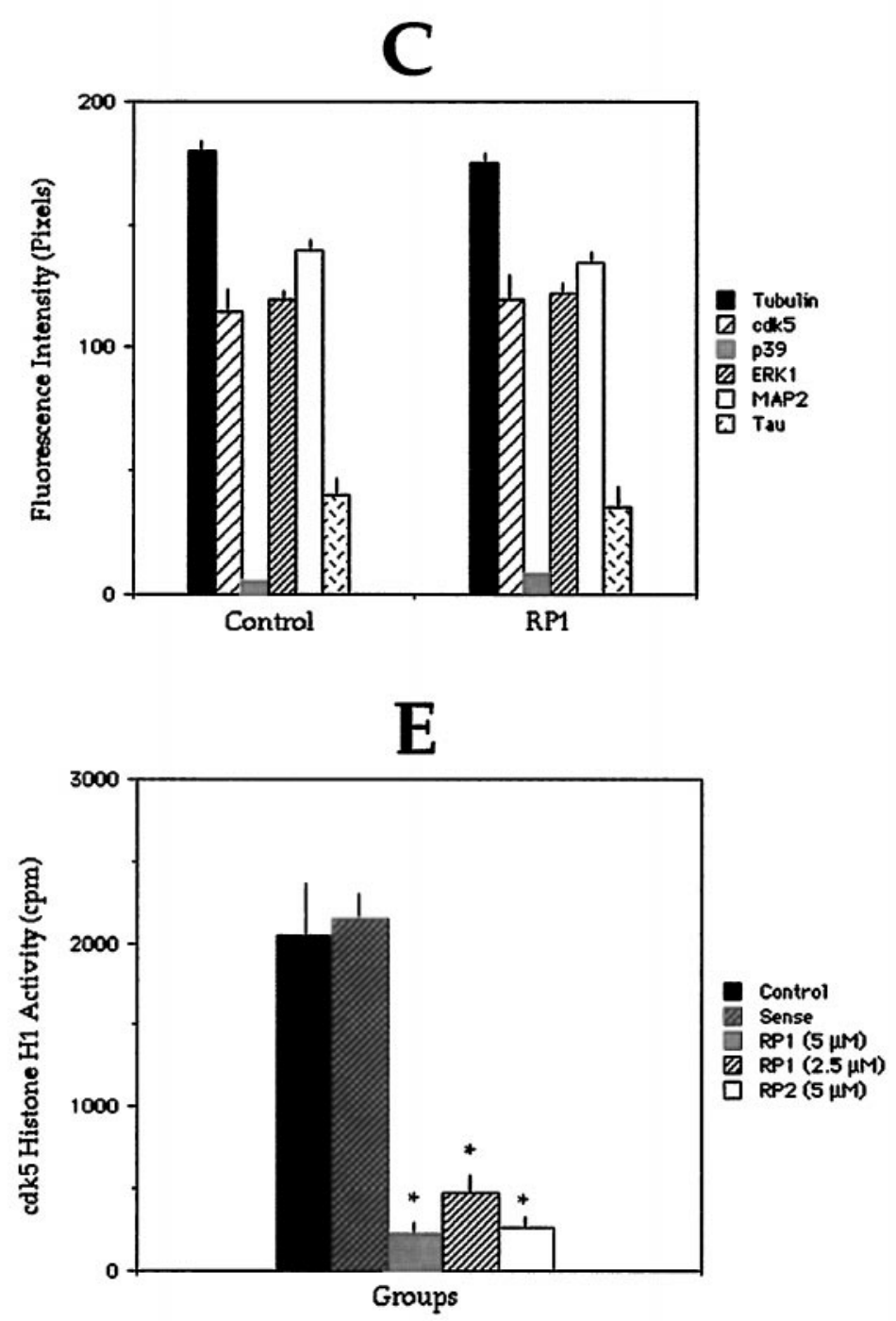

Figure 2. A, Effect of the antisense oligonucleotide RP1 $(5 \mu \mathrm{M})$ on p35 protein levels as revealed by Western blot analysis of cell extracts obtained from cultured cerebellar macroneurons growing on laminin and reacted with the C19 antibody diluted 1:200. Lane 1, Control nontreated, 24 hr after plating; lane 2, sense-treated, $24 \mathrm{hr}$ after plating; lane 3, RP1-treated, $12 \mathrm{hr}$ after plating; lane 4, RP1-treated, $24 \mathrm{hr}$ after plating; lane 5, RP1-treated, $36 \mathrm{hr}$ after plating. Five micrograms of total cellular protein were added in each lane. $B$, Quantitative fluorescence measurements showing the effect of the antisense oligonucleotides RP1 $(5$ or $2.5 \mu \mathrm{M})$ or RP2 $(2.5 \mu \mathrm{m})$ on p35 immunofluorescence. Fluorescence intensity measurements were performed in the cell body 4, 12, and $24 \mathrm{hr}$ after plating; a total of 100 cells was measured for each time point and experimental condition. $C$, Quantitative fluorescence measurements showing the relative levels of tubulin, cdk5, p35, ERK1, MAP2, and tau in control and RP1-treated cells. Figure legend continues. 
residues 289-307 mapping at the $\mathrm{C}$ terminus of $\mathrm{p} 35$ is shown in Figure $1 A$. The antibody recognizes a single band of $\sim 35 \mathrm{kDa}$ when whole-cell extracts of cultured cerebellar macroneurons growing on polylysine are resolved in SDS-PAGE, blotted, and immunostained with the anti-p35 antibody (Fig. 1A, lanes 1-3). The staining generated by this antibody is greatly inhibited by neutralization with purified peptide (Fig. $1 A$, lane 4 ). Quantitative Western blot analysis revealed that embryonic day 15 (E15) cerebellar cells express low levels of p35 at the time of plating and that a significant increase occurs after the cells have developed in culture for $>2 \mathrm{~d}$. This increase in p35 protein levels closely parallels the increase in cdk5 activity and in axonal length observed after the initial establishment of neuronal polarity in cultured cerebellar macroneurons (Table 1; see also Pigino et al., 1997).

More importantly, our results show that when cerebellar macroneurons are cultured on a laminin-containing substrate, a dramatic increase in p35 protein levels is detected (Fig. $1 B$, lanes 1-6; Table 1). This phenomenon is also accompanied by an acceleration in the time course of p35 expression; thus, Western blot analysis of whole-cell extracts obtained from neurons cultured in the presence of laminin for 4, 10, or $20 \mathrm{hr}$ and probed with the anti-p35 antibodies revealed a considerable and significant increase in the levels of p35 when compared with the ones detected at equivalent time points in neurons maintained on polylysine alone (Fig. $1 B$ ). The increase in p35 protein levels detected in cerebellar macroneurons growing on laminin is significantly inhibited when the cells are incubated with an affinitypurified rabbit polyclonal antibody against $\beta-1$ integrin (Table 1).

It is unlikely that the increase in p35 protein levels induced by laminin is the result of an overall increase in protein synthesis, because no changes in the levels of cdk5 (Pigino et al., 1997), casein kinase II (Pigino et al., 1997), MAP1b (DiTella et al., 1996), MAP2 (Pigino et al., 1997), $\alpha$-tubulin (Fig. 1B, lanes 1-6), or kinesin heavy chain (data not shown) are detected between neurons growing on laminin or polylysine alone. Northern blot analysis provided additional support to these findings and revealed that laminin rapidly stimulates p35 mRNA expression in cultured cerebellar macroneurons (Fig. 1C); as expected, this treatment has no effect on cdk5 mRNA levels (Fig. 1D).

It has recently been shown that neurons not only express p35, but also a highly related isoform, designated as p39 (Tang et al., 1995). Therefore, it became of interest to determine whether laminin enhances the expression of $\mathrm{p} 39$. To test for this possibility we prepared a polyclonal antibody against p39 using as immunogen a peptide corresponding to amino acid residues 349-367 mapping at the $\mathrm{C}$ terminus of the $39 \mathrm{kDa}$ isoform; this region of the p39 molecule shows no significant homology with the corresponding one of p35. Figure $1 E$ shows that the p39 polyclonal antibody recognizes a single band of $\sim 40 \mathrm{kDa}$ in Western blots of whole-brain homogenates. This analysis revealed that in the cerebral cortex or cerebellum the expression of the p39immunoreactive protein species is lower at late embryonic and early postnatal days but that it increases significantly afterward, reaching a peak during the second postnatal week, in which the highest levels are detected (Fig. 1C, lanes 1-5). In addition, Western blots of cell extracts obtained from cultures of cerebellar macroneurons revealed that these neurons express very low levels of p39 at the time of plating but that a significant increase occurs after the cells have developed in vitro for $>4 \mathrm{~d}$ (data not shown). More importantly, our results show that there are no significant differences in the levels of p39 between neurons cultured on polylysine alone or polylysine plus laminin (Fig. 1E, lanes 6-7).

Based on these observations it is likely that the increase in cdk5 activity observed in neurons growing on laminin (Pigino et al., 1997) is associated with an enhanced and selective expression of p35. However, other possibilities were also considered. For example, an enhancement of cdk5 activity may also result from a reduced expression of the mitotic inhibitor p27, whose expression increases in parallel with terminal neuronal differentiation and that is capable of suppressing cdk5 activity (Lee et al., 1996b). We think this is unlikely because no differences in p 27 protein levels were detected between neurons growing on laminin or polylysine alone (Fig. $1 F$, lanes $1-2$ ).

Alternatively, and because laminin may stimulate cdk5 activity by enhancing the expression of other cdk5 activators, like p67 (Shetty et al., 1994), we decided to examine the consequences of p35 suppression by antisense oligonucleotide treatment on the activity of cdk5 in cultured cerebellar macroneurons growing on laminin. Two different nonoverlapping phosphorothioate antisense oligonucleotides were fabricated. The sequences selected were specific for p35, but not for p39. As controls, we also obtained sense oligonucleotide sequences corresponding to both of the antisense sequences. The oligonucleotides were added directly to the culture medium in the presence of Lipofectin (see Materials and Methods) and renewed every 6 hr. Figure $2 A$ shows that the addition of the p35 antisense oligonucleotide RP1 at a dose of $5 \mu \mathrm{M}$, but not of the corresponding sense-strand oligonucleotide, to cells growing on laminin produces a significant reduction in p35 protein levels as determined by Western blot analysis of whole-cell homogenates reacted with either the rabbit antiserum C-19 or the N-20 antibody. Inhibition of p35 expression becomes evident after $16 \mathrm{hr}$ of antisense treatment, and by $36 \mathrm{hr}$ only trace amounts of protein are detected in the cell homogenates. In addition, to test for specificity, quantitative fluorescence measurements were performed, and the relative levels of p35, p39, cdk5, ERK1, and several cytoskeletal proteins were evaluated at different time points after the addition of the antisense or sense oligonucleotides. The results obtained, shown in Figure $2 B$, indicate that although both of the antisense sequences are effective in reducing p35 protein levels in a dose-dependent manner, neither of the sense sequences detectably altered p35 protein levels. In addition, neither of the antisense sequences nor the sense sequences resulted in diminutions of the levels of cdk5, p39, ERK1, tubulin, MAP1b, MAP2, or tau protein levels (Fig. 2C). Having shown that the p35 antisense oligonucleotides effectively and selectively inhibit p35 expression, we decided to examine cdk5 activity in p35-suppressed cultured cerebellar macroneurons maintained on a laminin-containing substrate. For such a purpose, cdk5 was immunoprecipitated from sense- and antisensetreated cultures; the ability of the cdk5 immunoprecipitates to phosphorylate histone $\mathrm{H} 1$ was then evaluated. The results obtained showed high cdk5 histone $\mathrm{H} 1$ kinase activity in the immunoprecipitates from sense-treated cultures and a significant decrease of such an activity in the ones obtained from the antisensetreated cultures (Fig. 2D,E).

An additional possibility to consider is that the increase in p35 protein levels and the associated cdk5-enhanced histone $\mathrm{H} 1 \mathrm{ki}$ nase activity (Pigino et al., 1997) observed in neurons growing on laminin are the result of an enhanced rate of neurite extension and not a direct consequence of laminin activity. To distinguish between these possibilities, the following experiment was performed. In previous studies we have shown that the acute addition 


\begin{abstract}
Table 2. Changes in p35 protein levels after the acute addition of laminin to control and tau/MAP1b suppressed cerebellar macroneurons growing on polylysine
\end{abstract}

Hours after the addition of laminin to the culture medium

\begin{tabular}{lcc}
\cline { 2 - 2 } Groups & 0 & 24 \\
\hline Non-treated & \\
$\quad$ Axonal length & $110 \pm 12$ & $230 \pm 10$ \\
p35 protein levels & $720 \pm 80$ & $1050 \pm 110$ \\
Non-treated plus laminin & \\
(20 $\mu \mathrm{g} / \mathrm{ml})$ & \\
Axonal length & $115 \pm 10$ & $360 \pm 24^{*}$ \\
p35 protein levels & $660 \pm 70^{*}$ & $2300 \pm 120^{*}$ \\
MAP1b and tau antisense-treated & & \\
plus laminin $(20 \mu \mathrm{g} / \mathrm{ml})$ & & $85 \pm 10^{*}$ \\
Axonal length & $65 \pm 5^{*}$ & $2300 \pm 85$ \\
p35 protein levels & $650 \pm 60$ &
\end{tabular}

$\overline{\text { All experiments started } 24 \mathrm{hr} \text { after plating. Length values are expressed in microme- }}$ ters. Data represent the mean \pm SEM. A total of 100 cells was analyzed per time point and experimental condition. p35 protein levels were determined by quantitative Western blotting using ${ }^{125} \mathrm{I}$ protein A, as described in Materials and Methods. Each value represents the mean \pm SEM from measurements of five samples obtained from cerebellar cultures grown on $25 \mathrm{~mm}$ glass coverslips. Values are expressed in micrograms per milligram of total cellular protein. The antisense oligonucleotides were added to the culture medium $4 \mathrm{hr}$ after plating and replenished every $12 \mathrm{hr}$ until the end of the experiment. For suppressing MAP1b we used the antisense oligonucleotide designated As1 (see DiTella et al., 1992), whereas for suppressing tau we used the antisense oligonucleotide RT11/14 (Caceres and Kosik, 1990; Caceres et al., 1992; DiTella et al., 1996); both oligonucleotides were used at concentrations of $50 \mu \mathrm{M}$.

*Values significantly different from those found in the corresponding control group.

of laminin to the tissue culture medium of neurons growing on polylysine stimulates cdk5 activity and increases the rate of neurite extension (DiTella et al., 1996; Pigino et al., 1997). This enhanced neurite outgrowth response can be prevented if cells are treated with a combination of antisense oligonucleotides against the tau and MAP1b mRNAs (DiTella et al., 1996). We took advantage of this situation to test whether soluble laminin was capable of increasing p35 expression in neurons with low levels of tau and MAP1b, as well as a with a reduced rate of axonal growth. The results obtained clearly indicate that laminin is capable of enhancing p35 expression independent of the magnitude of the neurite outgrowth response that the cells display (Table 2).

\section{The subcellular localization of p35 in developing cerebellar macroneurons}

Previous studies have shown that in cultured cortical neurons (Nikolic et al., 1996) or cerebellar macroneurons (Pigino et al., 1997), as well as during in situ cerebellar development (Matsushita et al., 1995), cdk5 redistributes from the cell body toward axonal growth cones during process formation. Although a similar phenomenon has been described for p35 in cultured cortical neurons (Nikolic et al., 1996), the situation appears to be different in the case of in situ developing neurons because immunohistochemical studies have failed to detect significant levels of p35 immunoreactivity within axons or growth cones; by contrast, high p35 immunolabeling was observed in cell bodies and dendrites of adult neurons (Tomizawa et al., 1996). This apparent discrepancy may be related with the fact that no immunocytochemical study has examined the subcellular distribution of p35 in embryonic brain (or cerebellar) tissue. Therefore, to clarify this point and obtain further evidences about the participation of p35 during laminin-stimulated cdk5 activation, the subcellular localization of p35 in cultured cerebellar macroneurons was analyzed by confocal microscopy; in addition, subcellular fractionation techniques were used to isolate growth cones from the embryonic cerebral and cerebellar cortex and to determine by Western blotting the presence of the $\mathrm{cdk} 5 / \mathrm{p} 35$ kinase.

In neurons growing on polylysine, light immunoreactivity for p35 is detected during the first $48 \mathrm{hr}$ after plating; in these cells, most of the labeling is found within the cell body, including the nucleus, but absent from either minor processes or axons (Fig. $3 A-D)$. However, after $48 \mathrm{hr}$ when most of the neurons have already extended an axon of $>120 \mu \mathrm{m}$, a significant change in the intensity of the labeling and in the distributional pattern of p35 is detected in the majority of the cells. Thus, at this stage, an intense staining of the cell body and axonal growth cones is observed with the antibodies against p35 used at concentrations of 0.2-0.5 $\mu \mathrm{g} / \mathrm{ml}$ (Fig. $3 E-G$ ); at neuritic tips this immunolabeling is particularly prominent within the peripheral regions of growth cones. At higher antibody concentrations $(1-2 \mu \mathrm{g} / \mathrm{ml}) \mathrm{p} 35$ is also detected in microspikes located within the distal third of growing axons, as well as within the growth cones of minor processes, the neurites that will lately develop into dendrites (Cáceres et al., 1991, 1992).

To test whether the localization of p35 at the periphery of axonal growth cones involves a plasma membrane association, a mild extraction protocol using saponin was used. This procedure selectively removes cytosolic proteins but retains cytoskeletal membrane interactions (Nakata and Hirokawa, 1987; Brandt et al., 1995; Pigino et al., 1997). In saponized cells, both p35 antibodies stain the actin-rich peripheral regions of growth cones, as well as microspikes or filopodial extensions emerging from lamellipodial veils (Fig. 3H,I).

Western blot analysis of growth cone particles isolated by subcellular fractionation according to the procedures described by Pfenninger et al. (1983) (Lohse et al., 1996; see Materials and Methods) and probed with antibodies specific for cdk5 or p35, revealed the presence of the $c d k 5 / \mathrm{p} 35$ kinase in growth cones obtained from either the cerebral cortex or cerebellum (Fig. 4A); a very low signal for $\mathrm{p} 39$ was also detected in these preparations (Fig. $4 A$ ). To test for the purity of the GCP fraction we analyzed the distribution of several well established growth cone markers, namely c-src (Helmke and Pfenninger, 1996) or $\beta g c$ (Quiroga et al., 1995; Mascotti et al., 1997); both proteins were highly enriched in the growth cone extracts containing cdk5 or p35 (Fig. $4 A$ ); by contrast high molecular weight MAP2 was undetectable in these preparations (Fig. $4 A$ ). Moreover, to discard possible contaminations of GCPs with membranes of relatively low buoyant densities, we assayed GCPs for the presence of a well established Golgi marker, such as the protein designated as TGN-38 (Horn and Banting, 1994). As shown in Figure 4A, this protein was completely absent from this preparation.

In a complementary series of experiments we used quantitative fluorescence techniques to measure the relative amount of p35 at neuritic tips of axons from neurons growing on either polylysine or laminin. The results obtained, which are shown in Figure $4, B$ and $C$, indicate that laminin selectively and significantly increases the relative amount of p35 associated with the subcortical cytoskeleton of axonal growth cones. This analysis also revealed that laminin not only increases the intensity of p35 immunolabeling, but that it selectively accelerates the time course of appearance of p35 immunofluorescence at the distal 

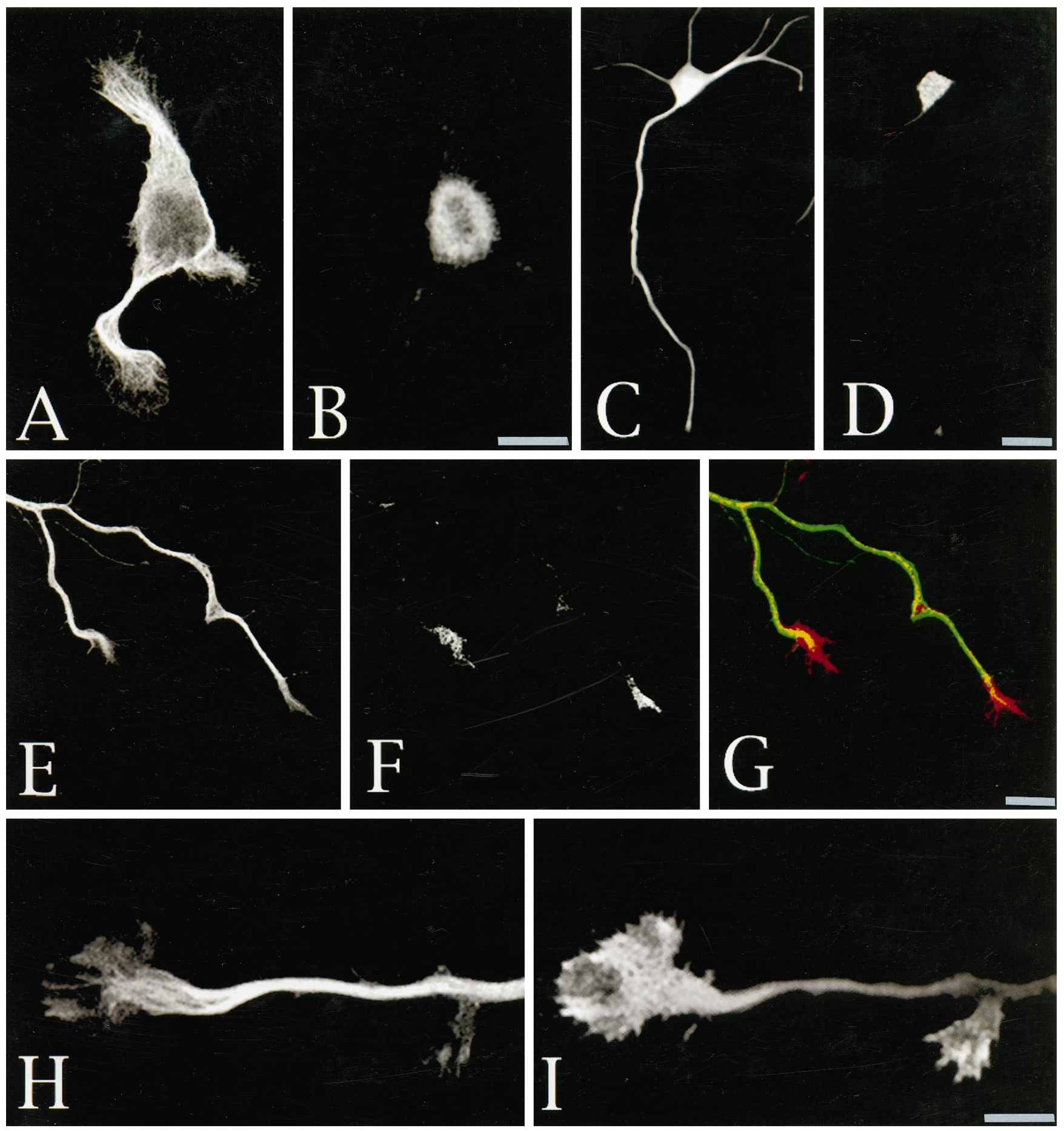

Figure 3. Distribution and subcellular localization of p35 in cerebellar macroneurons growing on polylysine. $A-D$, Confocal micrographs showing the distribution of tyrosinated $\alpha$-tubulin $(A, C)$ and p35 $(B, D)$ in cerebellar macroneurons maintained in culture for 36 hr. Note than in both stage II $(A$, $B)$ and in stage III $(C, D)$ neurons, p35 is mainly localized to the cell body; there is no staining of minor processes or the axon. $E, F$, Confocal images showing the distribution of tyrosinated $\alpha$-tubulin $(E)$ and $\mathrm{p} 35(F)$ at the distal end of a growing axon of a cerebellar macroneuron maintained in culture for $48 \mathrm{hr}$. At this stage of neuritic development p35 immunolabeling is present in the cell body and within axonal growth cones. $G, R e d$-green overlay of the images shown in $E$ and $F$. $H, I$, High-power confocal micrographs showing the distribution of tyrosinated $\alpha$-tubulin $(H)$ and p35 $(I)$ at the distal end of a growing axon. Note that p35 immunolabeling is highly enriched at the growth cone periphery in regions almost devoid of microtubules. For this experiment the cells were extracted with $0.02 \%$ saponin before fixation. Scale bars, $10 \mu \mathrm{m}$.

end of growing axons. Under this experimental condition, it was possible to detect high p35 immunolabeling within axonal growth cones, as soon as 4-6 hr after plating, when a significant proportion of cells have already developed an axon-like neurite of $>80 \mu \mathrm{m}$.

\section{p35 suppression inhibits laminin-enhanced axonal elongation and MAP1b phosphorylation}

In a previous study (Pigino et al., 1997) we have shown that in neurons growing on laminin cdk5 and mode I phosphorylated 
A
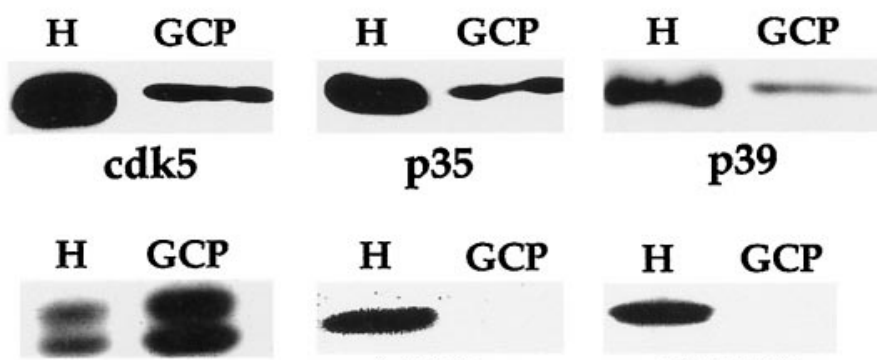

c-src

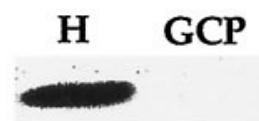

MAP2

B
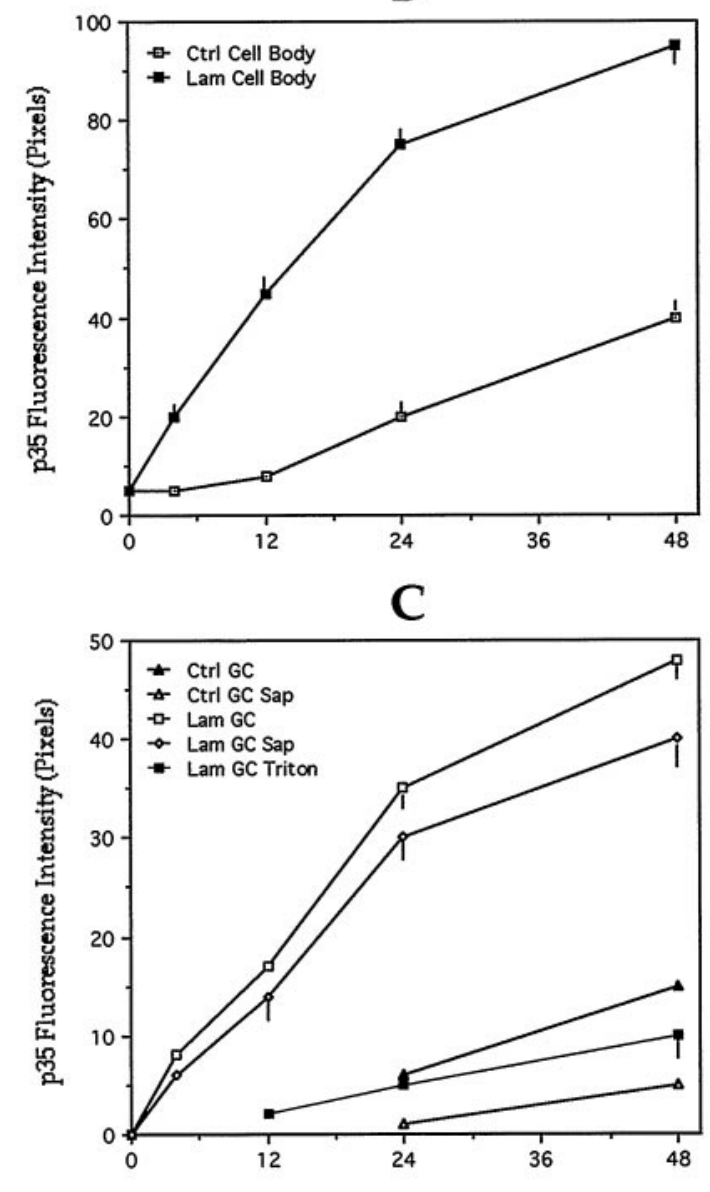

Hours in vitro

Figure 4. A, Western blots of total brain homogenates $(H)$ and growth cone particles $(G C P)$ reacted with antibodies against cdk5 (dilution 1:200, $0.5 \mu \mathrm{g} / \mathrm{ml}$ ), p35 (dilution 1:200, $0.5 \mu \mathrm{g} / \mathrm{ml}$ ), p39 (dilution 1:50, $2 \mu \mathrm{g} / \mathrm{ml}$ ), c-src (dilution 1:100, $1 \mu \mathrm{g} / \mathrm{ml}$ ), MAP2 (dilution 1:500), and TGN38 (dilution 1:200). The lanes reacted with antibodies against cdk5, p35, c-src, MAP2, and TGN38 were loaded with $10 \mu \mathrm{g}$ of total cellular protein; the ones reacted with the p39 antibody were loaded with $75 \mu \mathrm{g}$ of total cellular protein. The total brain homogenate and the GCP were obtained from E18 rat embryos as described in Materials and Methods. B, Average intensity measurements of $\mathrm{p} 35$ immunofluorescence within the cell body of cerebellar macroneurons cultured on polylysine $(\mathrm{Ctrl})$ or on a laminincontaining substrate ( $\mathrm{Lam}$ ); immunofluorescence was performed in cells fixed before extraction with detergents. A total of 50 cells was measured per time point and experimental condition. Each value represents the mean \pm SEM. $C$, Average intensity measurements of p35 immunofluorescence within growth cones $(G C)$ of axons of cerebellar macroneurons
MAP1b (e.g., phosphorylation at PDPK epitope; Ulloa et al., 1993a,b) increase significantly at the distal end of growing axons in parallel with rapid axonal elongation. Besides, cdk5 suppression significantly reduces laminin-enhanced axonal elongation and the mode I of MAP1b phosphorylation (Ulloa et al., 1993a,b; Pigino et al., 1997). Based on these observations we have proposed that at least one mechanism by which cdk5 may participate in axonal extension involves the regulation of MAP1b phosphorylation at the distal end of the growing axon. Therefore, to obtain further evidences about this proposal we decided to examine the consequences of p35 suppression on process formation and MAP1b phosphorylation in cerebellar macroneurons growing on a laminin-containing substrate.

Under this condition p35 suppression significantly and selectively reduces laminin-stimulated axonal extension (Fig. 5A). This phenomenon becomes evident $20-24 \mathrm{hr}$ after the addition of the antisense oligonucleotides, being highly coincident with the reduction in $\mathrm{p} 35$ protein levels (Fig. $5 B$ ). By contrast, no inhibition of axonal elongation was observed when equivalent cultures were treated with the corresponding sense oligonucleotides or with a p39 antisense oligonucleotide (Fig. $5 A, B$ ). We also failed to detect an inhibition of axonal elongation when the RP1 or RP2 oligonucleotides were added from the time of plating, and for a period of $24 \mathrm{hr}$, to cerebellar macroneurons growing on polylysine alone (data not shown).

Our observations (Fig. $5 C, D$ ) also show that a $48 \mathrm{hr}$ treatment of cerebellar macroneurons growing on a laminin-containing substrate with the RP1 antisense oligonucleotide $(5 \mu \mathrm{M})$ significantly reduces the labeling generated by the mAb 150 that recognizes a phosphorylated mode I epitope on the MAP1b molecule (Ulloa et al., 1993a,b; Pigino et al., 1997) while it increases the one observed with the rabbit antiserum 531, which recognizes a PDPK phosphorylatable MAP1b epitope when it is dephosphorylated (Ulloa et al., 1993a,b; Pigino et al., 1997).

Because at axonal tips the cdk5/p35 complex is highly enriched in the lamellipodial veil of growth cones, we decided to examine whether dephosphorylated MAP1b was also present in this subcellular compartment. In previous studies we have shown that dephosphorylated MAP1b distributes throughout the cell, localizing in the cell body, minor neurites, and axonal processes; it should be noted that most of the dephosphorylated MAP1b present in developing cerebellar macroneurons is lost when cells are extracted with Triton X-100 under microtubule stabilizing conditions before fixation (DiTella et al., 1996; Pigino et al., 1997). However, when the cells are extracted with $0.02 \%$ saponin under conditions that preserve cytoskeletal-membrane interactions (Nakata and Hirokawa, 1987; Pigino et al., 1997) 531 immunolabeling is detected throughout the neurons including neuritic tips (Fig. 6). High resolution fluorescence microscopy, digital image processing, and ratio image analysis of cells double labeled with the 531

cultured on polylysine (Ctrl) or a laminin-containing substrate (Lam). Immunofluorescence was performed in cells fixed before $(\mathrm{Ctrl} \mathrm{GC} / \mathrm{Lam}$ $G C$ ) or after saponin (Ctrl GC Sap/Lam GC Sap) or Triton X-100 (Lam $G C$ Triton) extraction performed under conditions that stabilize the cytoskeleton (see Materials and Methods). Note that in cells growing on laminin a significant amount of p35 immunofluorescence remains associated with the cytoskeleton after saponin extraction performed under conditions that preserve cytoskeletal-membrane interactions. A total of 50 cells was measured per time point and experimental condition. Each value represents the mean \pm SEM. 
A

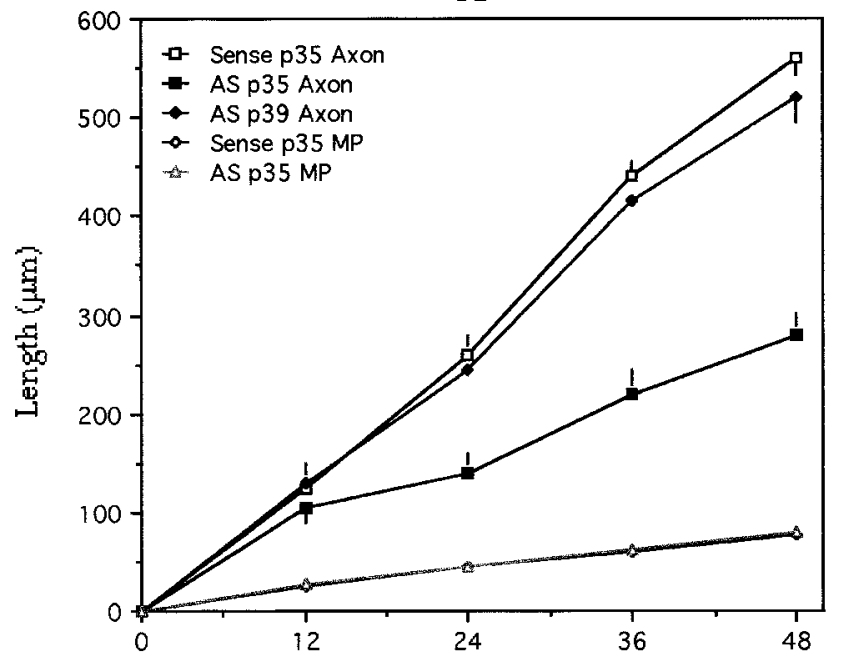

C

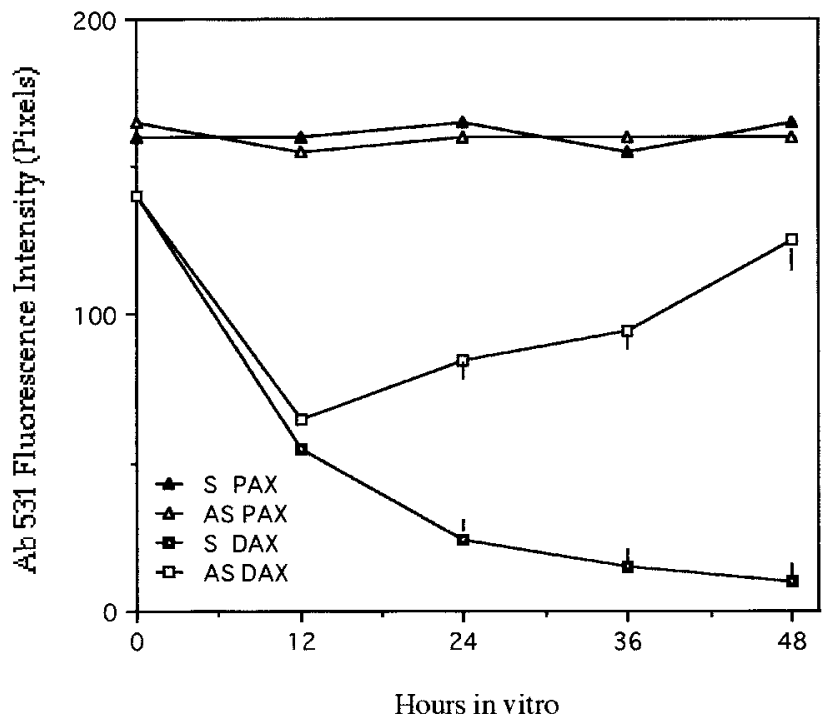

B

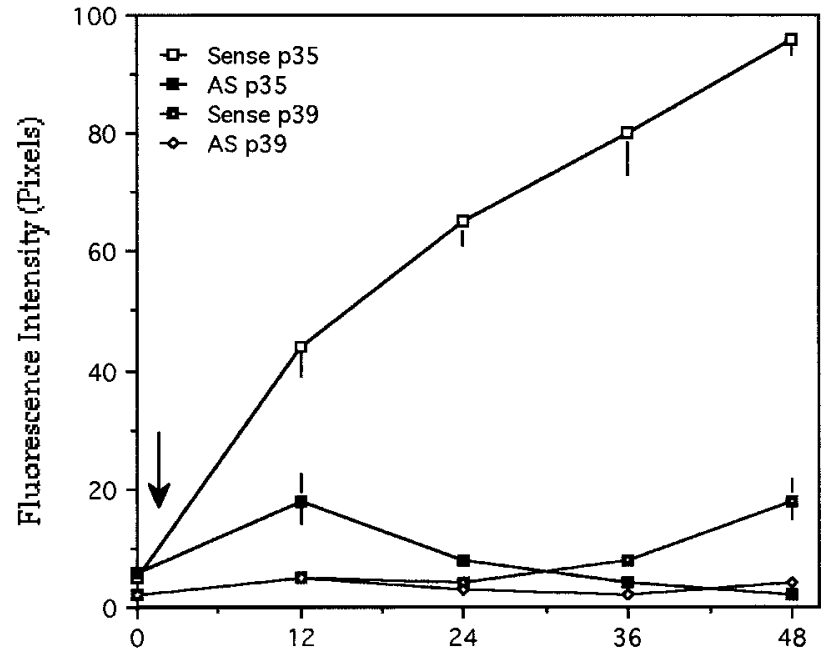

D

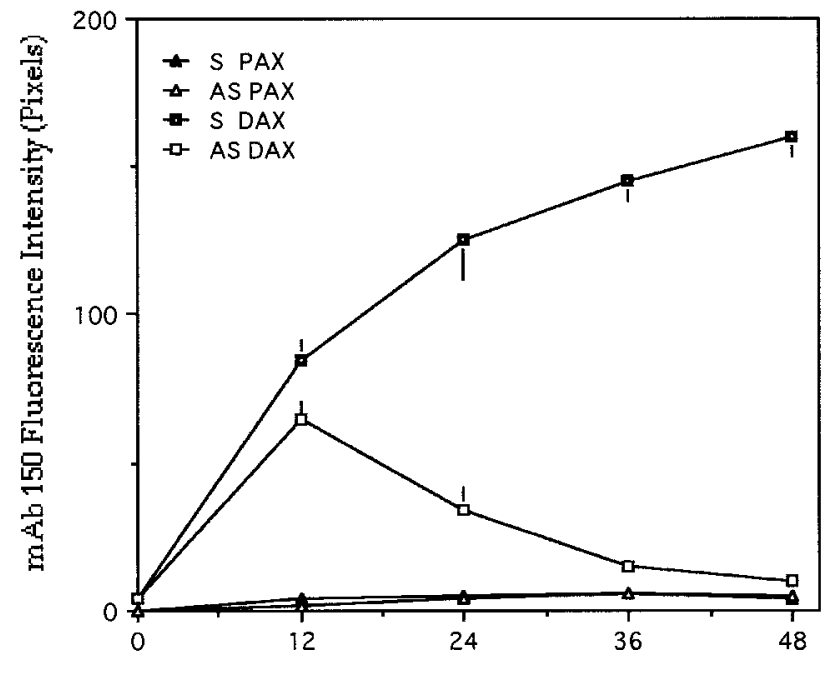

Hours in vitro

Figure 5. A, Graph showing that suppression of $\mathrm{p} 35$, but not of $\mathrm{p} 39$, selectively inhibits axonal elongation in cerebellar macroneurons growing on a laminin-containing substrate. Open squares, Axonal length in sense-treated cultures; solid squares, idem but in RP1-treated cultures (5 $\mu \mathrm{M})$; solid diamonds, idem but in p39 antisense-treated cultures $(5 \mu \mathrm{M})$; total length of minor processes per cell in p35 sense-treated cultures; idem but in RP1-treated cultures. A total of 100 cells was measured per time point and experimental condition. Each value represents the mean \pm SEM. $B$, Average intensity measurements of p35 and p39 immunofluorescence in cerebellar macroneurons treated with p35 (RP1, $5 \mu \mathrm{M})$ or p39 (5 $\mu \mathrm{M})$ antisense oligonucleotides. Measurements were performed in the cell body, and a total of 50 cells were analyzed per time point and experimental condition. Each value represents the mean \pm SEM. $C$, Average intensity measurements of PDPK-dephosphorylated MAP1b immunofluorescence in p35 sense- $(S)$ and antisense- $(A S)$ treated cultures; cells were stained with the polyclonal antibody 531 (Ab 531). Measurements were performed in proximal (PAX) and distal $(D A X)$ axonal segments. Note that in the p35 antisense-treated neurons, 531 immunolabeling increases at the distal axonal segment. A total of 50 cells was analyzed per time point and experimental condition; each value represents the mean \pm SEM. Oligonucleotides were used at a concentration of $5 \mu \mathrm{M}$. $D$, Average intensity measurements of PDPK-phosphorylated MAP1b immunofluorescence in p35 sense- $(S)$ and antisense- $(A S)$ treated cultures; cells were stained with the mAb 150 . Measurements were performed in proximal $(P A X)$ and distal $(D A X)$ axonal segments. Note that in the p35 antisense-treated neurons mAb 150 immunolabeling decreases at the distal axonal segment; also note the absence of mAB 150 immunolabeling in proximal axonal segments of both sense- and antisense-treated cultures. Oligonucleotides were used at a concentration of $5 \mu \mathrm{M}$. A total of 50 cells was analyzed per time point and experimental condition; each value represents the mean \pm SEM.

antiserum and an mAb against tyrosinated $\alpha$-tubulin clearly revealed the presence of dephosphorylated MAP1b within the lamellipodial veils of growth cones; confocal microscopy confirmed these observations and also revealed the presence of intense 531 immunolabeling in microspikes emerging from the periphery of growth cones (Fig. $6 D$, insert; $H$ ).

\section{DISCUSSION}

\section{p35 participation in axonal elongation}

p35 is a neuron-specific regulatory subunit of cdk5 that is expressed in postmitotic neurons but is absent in proliferating neuronal progenitors (Lew et al., 1994; Tsai et al., 1994; Tomi- 

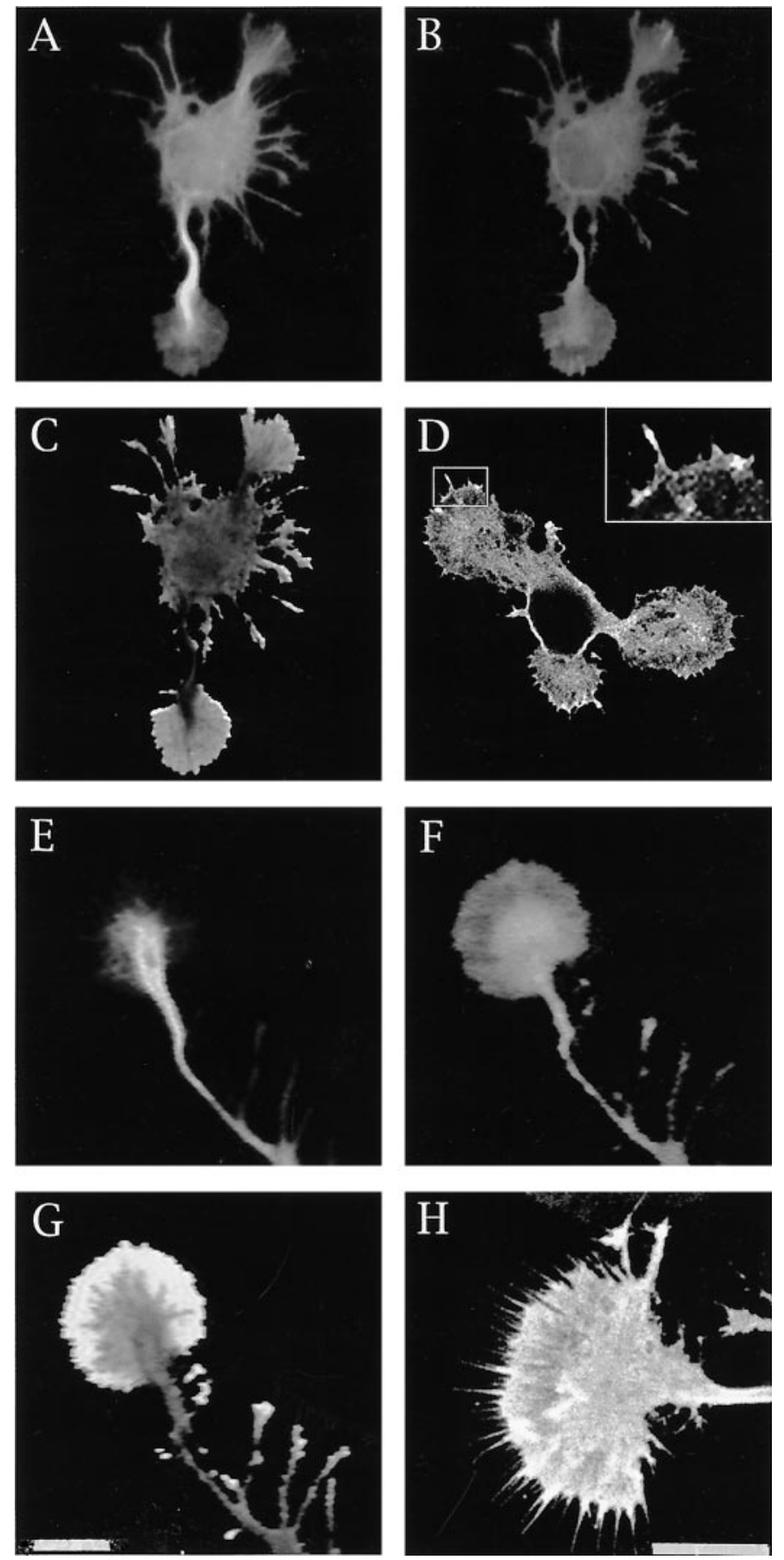

Figure 6. $A, B$, Double immunofluorescence micrographs showing the distribution of tyrosinated $\alpha$-tubulin $(A)$ and PDPK-dephosphorylated MAP1b in a stage II cerebellar macroneuron cultured on polylysine. The cell was extracted with saponin before fixation under conditions that preserve cytoskeletal-membrane interactions. MAP1b was labeled with the rabbit antiserum 531 used at a dilution of 1:500. For this experiment the images were formed on the faceplate of an SIT camera and digitized directly into the Metamorph Image Processor. Using image $B$ as numerator and image $A$ as denominator, we applied the ratio image menu of the processor to generate the image shown in $C$, which clearly reveals the presence of dephosphorylated MAP1b within the lamellipodial veil of growth cones. $D$, A confocal image of a stage II cerebellar macroneuron also showing the presence of PDPK-dephosphorylated MAP1b within the lamellipodial veils of growth cones; the insert shows the presence of 531 immunolabeling (dilution 1:500) within microspikes located at the periphery of lamellipodial veils. $E, F$, Double immunofluorescence micrographs showing the distribution of tyrosinated $\alpha$-tubulin $(E)$ and PDPK- zawa et al., 1996; Delalle et al., 1997). Based on the analysis of the spatiotemporal pattern of p35 mRNA distribution (Tsai et al., 1994; Delalle et al., 1997) and of the phenotype of mice lacking p35, a key role for the cdk5/p35 kinase in proper neuronal migration has been established (Chae et al., 1997). Thus, examination of mice lacking p35, and, thus, p35/cdk5 activity, has revealed severe cortical lamination defects, including a reversed packing order of cortical neurons, such that earlier born neurons reside in superficial layers and lately generated ones occupy deep layers (Chae et al., 1997).

A second major proposed role for the $\mathrm{cdk} 5 / \mathrm{p} 35$ kinase is the regulation of neuritic development (Nikolic et al., 1996; Delalle et al., 1997). In favor of this view, previous studies have established the existence of a high degree of temporal correlation among p35 mRNA expression, the induction of cdk5 activity, and the formation of major axonal tracts (Tsai et al., 1993; Delalle et al., 1997; Tomizawa et al., 1997); besides, expression of a p35 antisense construct in cultured cortical neurons reduces neurite outgrowth (Nikolic et al., 1996). Although the present results are consistent with these observations, they suggest that the cdk5/p35 complex, rather than having an essential role in process formation (Nikolic et al., 1996), acts as a modulator of axonal elongation. A recent study showing that in immortalized hippocampal cells, p35 is sufficient but not essential for inducing neurite outgrowth also favors this view (Xiong et al., 1997). In the case of cerebellar macroneurons, we found a high degree of spatial and temporal correlation between the expression of the cdk5/p35 kinase and axonal elongation when the neurons were maintained on a laminin-containing substrate; by contrast, such a correlation was not observed in neurons growing on polylysine alone in which the expression of the cdk5/p35 kinase occurs after the initial extension of neurites and the establishment of neuronal polarity (this study; see also Pigino et al., 1997). Besides, and perhaps more importantly, two nonoverlapping antisense oligonucleotides that effectively diminished the levels of p35 were capable of selectively suppressing laminin-enhanced axonal elongation, without altering the normal extension of minor neurites or the ability of cerebellar macroneurons to differentiate one of the minor processes into an axon-like neurite. As with any study involving the use of antisense oligonucleotides, it was important to establish that the observed effects were not related to a diminution in the health of the cultures. Several observations suggest that the p35 antisense oligonucleotides specifically and selectively blocked the expression of p35. First, sequence analysis of the regions of the rat p35 mRNA selected for designing the antisense oligonucleotides revealed no significant homology with any other reported sequence. Besides, none of the S-modified antisense oligonucleotides used in this study contains four contiguous guanosines residues, which are believed to increase oligomer affinity to proteins and, hence, generate nonspecific inhibitory effects (Wagner, 1995). Second, the antisense oligonucleotide treatment dramatically reduced p35 protein levels without altering the levels of several other proteins, including cdk5, p39, tubulin, MAP1b, MAP2, tau, and ERK1. Third, the effects of the antisense oligonucleotides were

\section{$\leftarrow$}

dephosphorylated MAP1b $(F)$ within an axonal tip of a cerebellar macroneuron growing on polylysine and prepared for immunocytochemistry as described previously. $G$, Ratio image analysis clearly reveals the presence of dephosphorylated MAP1b within the peripheral lamellipodial veil of axonal growth cones. $H$, Confocal image also showing the presence of PDPK-dephosphorylated MAP1b at the periphery of axonal growth cones. Scale bars, $10 \mu \mathrm{m}$. 
dose-dependent and not observed when the cells were treated with equivalent doses of the corresponding "sense" oligonucleotides. Finally, the antisense treatment was not effective in reducing axonal length when it was applied to neurons that express low levels of p35 and, hence, display low cdk5 activity, e.g., neurons cultured on polylysine for up to $48 \mathrm{hr}$.

Our results also suggest that p35, and not the p39 isoform, is involved in regulating axonal extension in neurons growing on a laminin-containing substrate. Thus, no decreases in axonal length or in the time course of axonal formation were detected in cerebellar macroneurons treated with a p39 antisense oligonucleotide. This may not be surprising because p39 is predominantly expressed in polarized neurons, and not during the initial stages of process formation, both in situ and in vitro (Cai et al., 1997; this study). Although this analysis suggests that p39 has no essential role in neurite outgrowth and axonal extension, it does not rule out the possibility of p39 being involved in the maintenance of more mature neurites or in process formation in response to a different type of environmental cue. In this regard, it is worth noting that in immortalized hippocampal pyramidal cells p39, rather than $\mathrm{p} 35$, is both necessary and sufficient for promoting neurite outgrowth in response to basic fibroblast growth factor (Xiong et al., 1997).

Suppression of either cdk5 (Pigino et al., 1997) or p35 (this study), but not of p39, significantly decreases the levels of PDPKphosphorylated MAP1b. Because this phenomenon selectively occurs at the distal end of growing axons, it is likely that the $\mathrm{cdk} 5 / \mathrm{p} 35$ kinase regulates MAP1b phosphorylation within axonal growth cones. Thus, the time course of appearance of the cdk5/ p35 kinase within growth cones is highly coincident with a decrease of PDPK-dephosphorylated MAP1b and with an increase in PDPK-phosphorylated MAP1b. It is unlikely that the presence of the cdk5/p35 kinase within axonal growth cones of cultured neurons (this study; see also Nikolic et al., 1996; Pigino et al., 1997) represent some peculiarity related with their in vitro development, because Western blot analysis of growth cone particles clearly revealed the presence of both proteins in this compartment. Our results, and those of Nikolic et al. (1996), show that within growth cones most of the cdk5/p35 kinase is associated with the subcortical cytoskeleton but not with microtubules. This may be important in terms of previous studies that have shown that dephosphorylated MAP1b binds to microfilaments (Pedrotti and Islam, 1996) and not to microtubules (DiTella et al., 1996); besides, dephosphorylation kinetics suggests that the PDPK site, but not casein kinase II sites, negatively regulates the association of MAP1b with F-actin (Pedrotti and Islam, 1996). In accordance with that, we detected a significant association of PDPKdephosphorylated MAP1b with the growth cone subcortical cytoskeleton in neurons displaying low levels of p35 and, hence, of cdk5 activity. Therefore, it is tempting to speculate that the presence of an active cdk5/p35 complex within the growth cone subcortical cytoskeleton, as in the case of neurons growing on laminin, will phosphorylate MAP1b, detaching it from microfilaments and allowing its interaction with microtubules, an event that seems to be crucial for the participation of MAP1b in axonal elongation (DiTella et al., 1996: Pigino et al., 1997). However, it is worth noting that our results do not rule out the possibility of cdk5 participating in axonal elongation by additional mechanisms (see Pigino et al., 1997 for a discussion of this issue).

\section{Laminin regulation of p35 expression}

The present observations provide novel insights about the mechanisms by which laminin may regulate axonal elongation. Specif- ically, we show that laminin increases p35 mRNA and protein levels, a phenomenon that in turn enhances cdk5 activity, MAP1b phosphorylation, and axonal extension. The upregulation of p35 protein levels in neurons growing on a laminin-containing substrate seems not to be related with an overall increase in protein synthesis, because no effects were observed in the levels of total tubulin, MAP1b, MAP2, tau, cdk5, p39, and p27; nor it is the consequence of an increased rate of growth, because lamininstimulated p35 expression was also detected in neurons displaying a reduced rate of axonal elongation, such as in MAP1b- and tau-suppressed neurons. It is also unlikely that laminin increases cdk5 activity by stimulating the expression of other cdk5 activators, because it was completely prevented in neurons treated with antisense oligonucleotides specific for the p35 mRNA. Besides, our results also suggest that laminin-stimulated cdk5 activity is not the result of a reduced expression of a cdk5 inhibitor because no differences in the levels of p27 (Lee et al., 1996b) were detected between neurons growing on polylysine or laminin.

Our results suggest that one mechanism by which laminin increases p35 protein levels may involve the stimulation of p35 mRNA expression; this may not be an unusual phenomenon. In fact, a significant body of evidence exists showing that integrin activation after ECM binding can regulate expression of many genes (Ginsberg et al., 1995; Giancotti, 1997). For example, in anchorage-dependent cell lines, replating cells on fibronectin triggers expression of early immediate genes, such as c-fos and c-jun (Dike and Farmer, 1988; Dike and Ingber, 1996), whereas in rat kidney cells, cyclin A expression is specifically regulated by adhesion (Guadagno et al., 1993; see also Giancotti, 1997). In the specific case of neurons, a recent study has shown that laminin stimulates the expression of two mitochondrial proteins during process outgrowth (Weeks et al., 1997). Studies are in progress to determine the mechanisms by which laminin increases p35 mRNA levels.

\section{REFERENCES}

Avila J, Dominguez J, Diaz-Nido J (1994) Regulation of microtubule dynamics by microtubule-associated protein expression and phosphorylation during neuronal development. Int J Dev Biol 38:13-25.

Black M, Slaughter T, Fisher I (1994) Microtubule-associated protein 1b (MAP1b) is concentrated in the distal region of growing axons. J Neurosci 14:857-870.

Bottenstein J, Sato G (1979) Growth of a rat neuroblastoma cell line in a serum-free supplemented medium. Proc Natl Acad Sci USA 81:5613-5617.

Brandt R, Leger J, Lee G (1995) Interaction of tau with the neural plasma membrane mediated by tau's amino-terminal projection domain. J Cell Biol 131:1327-1340.

Brugg B, Reddy D, Matus A (1993) Attenuation of microtubuleassociated protein 1B expression by antisense oligodeoxynucleotides inhibits initiation of neurite outgrowth. Neuroscience 52:489-496.

Cáceres A, Kosik K (1990) Inhibition of neurite polarity by antisense oligonucleotides in primary cerebellar neurons. Nature 343:461-463.

Cáceres A, Potrebic S, Kosik K (1991) The effect of tau antisense oligonucleotides in primary cerebellar neurons. J Neurosci 11:1515-1523.

Cáceres A, Mautino J, Kosik K (1992) Suppression of MAP2 in cultured cerebellar macroneurons inhibits minor neurite formation. Neuron 9:607-618.

Cai XH, Tomizawa K, Tang D, Lu YF, Moriwaki A, Tokuda M, Nagahata S, Hatase O, Matsui H (1997) Changes in the expression of novel Cdk5 activator messenger RNA (p39nck5ai mRNA) during rat brain development. J Neurosci Res 28:355-360.

Carri N, Rubin K, Gullberg K, Ebendal T (1992) Neuritogenesis on collagen substrates. Involvement of integrin-like matrix receptors in retinal fibre outgrowth collagen. Int J Dev Neurosci 10:395-403.

Chae T, Kwon Y, Bronson R, Dikkes P, Li E, Tsai L (1997) Mice lacking $\mathrm{p} 35$, a neuronal specific activator of cdk5, display cortical lamination defects, seizures, and adult lethality. Neuron 18:29-42. 
Delalle I, Bhide P, Caviness J, Tsai L (1997) Temporal and spatial patterns of expression of p35, a regulatory subunit of cyclin-dependent kinase 5, in the nervous system of the mouse. J Neurocytol 26:283-296.

DiTella M, Feiguin F, Morfini G, Cáceres A (1994) Microfilament associated growth cone component depends upon tau for its intracellular localization. Cell Motil Cytoskeleton 29:117-130.

DiTella M, Feiguin F, Carri N, Kosik K, Cáceres A (1996) MAP1B/tau functional redundancy during laminin-enhanced axonal growth. J Cell Sci 109:467-477.

Dike LE, Farmer S (1988) Cell adhesion induces expression of growthassociated genes in suspension-arrested fibroblasts. Proc Natl Acad Sci USA 85:6792-6795.

Dike LE, Ingber D (1996) Integrin-dependent induction of early response genes in capillary endothelial cells. J Cell Sci 109:2855-2863.

Drubin D, Feinstein S, Shooter E, Kirschner M (1985) Nerve growth factor induced neurite outgrowth in PC12 cells involved the coordinate induction of microtubule assembly and assembly promoting factors. J Cell Biol 101:1799-1807.

Edelman W, Zervas M, Costello P, Roback L, Fisher I, Hammarback J, Cowan N, Davies P, Wainer B, Kucherlapati R (1996) Neuronal abnormalities in microtubule-associated protein $1 \mathrm{~B}$ mutant mice. Proc Natl Acad Sci USA 93:1270-1275.

Esmaeli-Azad B, McCarty J, Feinstein SC (1994) Sense and antisense transfection analysis of tau function: tau influences net microtubule assembly, neurite outgrowth, and neurite stability. J Cell Sci 107:869-879.

Ferreira A, Cáceres A (1991) Estrogen-enhanced neurite growth: evidence for a selective induction of tau and stable microtubules. J Neurosci 13:3112-3123.

Ferreira A, Busciglio J, Cáceres A (1989) Microtubule formation and neurite growth in cerebellar macroneurons which develop in vitro: evidence for the involvement of the microtubule-associated proteins MAP1a, HMW-MAP2 and tau. Dev Brain Res 49:215-228.

Giancotti F (1997) Integrin signaling: specificity and control of cell survival and cell cycle progression. Curr Opin Cell Biol 9:691-700.

Ginsberg M, Schwartz M, Schaller M (1995) Integrins: emerging paradigms of signal transduction. Annu Rev Cell Dev Biol 11:549-600.

Guadagno TM, Ohtsubo M, Roberts TM, Assoian RK (1993) A link between cyclin A expression and adhesion-dependent cell cycle progression. Science 362:1572-1575.

Harada A, Oguchi K, Okabe S, Kuno J, Terada S, Ohsima T, SatoYoshitake R, Takei Y, Noda T, Hirokawa N (1994) Altered microtubule organization in small caliber axons of mice lacking tau protein. Nature 369:488-491.

Helmke S, Pfenninger K (1996) Growth cone enrichment and cytoskeletal association of non-receptor tyrosine kinases. Cell Motil Cytoskeleton 30:194-207.

Hirokawa N (1994) Microtubule organization and dynamics dependent on microtubule-associated proteins. Curr Opin Cell Biol 6:74-81.

Horn M, Banting G (1994) Okaidaic acid lead to a fragmentation of the trans-Golgi network and an increase in expression of TGN38 at the cell surface. Biochem J 301:69-73.

Lee K, Rosales J, Tang D, Wang J (1996a) Interaction of cyclindependent kinase 5 (cdk5) and neuronal cdk5 activator in bovine brain. J Biol Chem 271:1538-1543.

Lee M, Nikolic M, Baptista C, Lai E, Tsai L, Massague J (1996b) The brain-specific activator $\mathrm{p} 35$ allows cdk5 to escape inhibition by $\mathrm{p} 27 \mathrm{Kip} 1$ in neurons. Proc Natl Acad Sci USA 93:3259-3263.

Lew J, Huang Q, Zhong Q, Winkfein R, Aebersold R, Hunt T, Wang J (1994) A brain-specific activator of cyclin-dependent kinase 5. Nature 371:423-426.

Li HN, Quiroga S, Pfenninger KH (1992) Variable membrane glycoproteins in different growth cone preparations. J Neurosci 12:2393-2402.

Lohse K, Helmke S, Wood M, Quiroga S, de la Houssaye B, Miller V, Negre-Aminou P, Pfenninger KH (1996) Axonal origin and purity of growth cones isolated from fetal rat brain. Dev Brain Res 96:83-96.

Maccioni R, Cambiazo V (1995) Role of microtubule-associated proteins in the control of microtubule assembly. Physiol Rev 75:835-864.

Mascotti F, Cáceres A, Pfenninger KH, Quiroga S (1997) Expression and distribution of IGF-1 receptors containing a b-subunit variant (bgc) in developing neurons. J Neurosci 17:1447-1459.
Matsushita M, Matsui H, Itano T, Tomizawa K, Masaaki T, Suwaki H, Wang J, Hatase O (1995) Developmental changes in cyclin dependent kinase 5 subcellular localization in rat cerebellum. NeuroReport 6:1267-1270.

Matus A (1988) Microtubule-associated proteins: their potential role in determining neuronal morphology. Annu Rev Neurosci 11:29-44.

Mitchison T, Kirschner M (1988) Cytoskeletal dynamics and nerve growth. Neuron 1:761-772.

Nakata T, Hirokawa N (1987) Cytoskeletal reorganization of human platelets after stimulation revealed by the quick-freeze deep-etch technique. J Cell Biol 106:1771-1780.

Nikolic M, Dudek H, Kwon Y, Ramos Y, Tsai L (1996) The cdk5/p35 kinase is essential for neurite outgrowth during neuronal differentiation. Genes Dev 10:816-825.

Pedrotti B, Islam K (1996) Dephosphorylated but not phosphorylated microtubule-associated protein MAP1B binds to microfilaments. FEBS Lett 388:131-133.

Pfenninger K, Ellis L, Johnson M, Friedman, L, Somlo S (1983) Nerve growth cones isolated from fetal rat brain. I. Subcellular fractionation and characterization. Cell 33:573-584.

Pigino G, Paglini G, Ulloa L, Avila J, Cáceres A (1997) Analysis of the expression, distribution and function of cyclin dependent kinase 5 (cdk5) in developing cerebellar macroneurons. J Cell Sci 110:257-270.

Quiroga S, Garofalo RS, Pfenninger KH (1995) Insulin-like growth factor I receptors of fetal brain are enriched in nerve growth cones and contain a b-subunit variant. Proc Natl Acad Sci USA 92:4309-4312.

Reichardt LF, Tomaselli K (1991) Extracellular matrix molecules and their receptors: functions in neural development. Annu Rev Neurosci 14:531-570.

Rocha M, Avila J (1995) Characterization of microtubule-associated protein phosphoisoforms present in isolated growth cones. Dev Brain Res 89:47-55.

Shetty K, Kaech S, Link W, Jaffe H, Flores C, Wray S, Pant H, Beuhausen $S$ (1995) Molecular characterization of a neuronal-specific protein that stimulates the activity of cdk5. J Neurochem 64:1988-1995.

Takei Y, Kondo S, Harada A, Inomata S, Noda T, Hirokawa N (1997) Delayed development of nervous system in mice homozygous for disrupted microtubule-associated protein 1B (MAP1B) gene. J Cell Biol 137:1615-1626.

Tanaka E, Sabry J (1995) Making the connection: cytoskeletal rearrangements during growth cone guidance. Cell 83:171-176.

Tang D, Young J, Lee K, Matsushita M, Matsuli H, Tomizawa K, Hatase O, Wang J (1995) An isoform of the neuronal cyclin-dependent kinase 5 (cdk5) activator. J Biol Chem 270:26897-26903.

Tomizawa K, Matsui H, Matsushita M, Lew J, Tokuda M, Itano T, Konishi R, Wang J, Hotase O (1996) Localization and developmental changes in the neuron-specific cyclin-dependent kinase 5 activator (p35ncka5) in the rat brain. Neuroscience 74:519-529.

Tsai L, Takahashi T, Caviness V, Harlow E (1993) Activity and expression pattern of cyclin-dependent kinase 5 in the embryonic mouse nervous system. Development 119:1029-1040.

Tsai L, Delalle L, Caviness V, Chae T, Harlow E (1994) p35 is a neural-specific regulatory subunit of cyclin-dependent kinase 5. Nature 371:419-423.

Ulloa L, Avila J, Diaz-Nido J (1993a) Heterogeneity in the phosphorylation of microtubule-associated protein MAP1B during rat brain development. J Neurochem 63:961-972.

Ulloa L, Diaz-Nido J, Avila J (1993b) Depletion of casein kinase II by antisense oligonucleotide prevents neuritogenesis in neuroblastoma cells. EMBO J 12:1633-1640.

Ulloa L, Ibarrola N, Avila J, Diaz-Guerra F (1994) Microtubuleassociated protein 1B (MAP1B) is present in glial cells phosphorylated different than in neurons. Glia 10:266-275.

Wagner R (1995) The state of the art in antisense research. Nat Med 1:1116-1118

Weeks BS, Burbelo P, Jucker M, Weiner MA, Roque F, Kleinman HK (1997) Laminin stimulates expression of two mitochondrial proteins during neurite outgrowth. Int J Dev Neurosci 14:365-374.

Xiong W, Pestell R, Rosner M (1997) Role of cyclins in neuronal differentiation of immortalized hippocampal cells. Mol Cell Biol 17:65856597. 